\title{
High Efficacy of Prednisolone in a Complicated Case of Weil Disease
}

\author{
Berat Ebik $^{1}$, Zülkif Tanrıverdi², Şuayp Öygen ${ }^{3}$, Yusuf Kayran ${ }^{4}$ \\ ${ }^{1}$ Department of Internal Medicine, İdil State Hospital, Şırnak, Turkey \\ ${ }^{2}$ Department of Cardiology, İdil State Hospital, Sirnak, Turkey \\ ${ }^{3}$ Department of Rheumatology, Akdeniz University Faculty of Medicine, Antalya, Turkey \\ ${ }^{4}$ Department of Neurology, İdil State Hospital, Şırnak, Turkey
}

To the Editor,

Leptospirosis is a self-limited zoonotic disease in mild cases, but the more severe form, known as Weil disease, can progress to multi-organ failure (1). Clinical signs and routine laboratory tests are non-specific. Therefore, in clinically suspected cases, antibiotic treatment must be immediately initiated. However, the antibiotic treatment may not be sufficient in Weil disease. Supportive treatment may be life-saving at this point.

A 19 year-old male presented with fever, nausea, vomiting, generalized jaundice, and reduced urinary output. Laboratory investigations revealed severe thrombocytopenia, elevated total bilirubin, and increased urea and creatinine levels. The history revealed that he had worked in a wooden fruit crate production facility. He resigned from his job and returned to his city 15 days before the clinical onset. He frequently scratched his hands and there were mice infestations where he used to work. He was initially diagnosed with Weil disease and treatment with ampicillinsulbactam (Ampisid, Mustafa Nevzat Medical; İstanbul, Turkey) was initiated at $3 \mathrm{gr} / \mathrm{day}$. On the third day of the follow-up, his platelet count decreased to 19,000 and his total bilirubin level rose to $14.7 \mathrm{mg} / \mathrm{dL}$; he had epistaxis. Since we could not perform plasmapheresis, prednisolone (Prednisolon, Actavis Medical; İstanbul, Turkey) was initiated at $1 \mathrm{mg} / \mathrm{kg}$ on the third day of admission. With the initiation of prednisolone, his platelet count began to rise and epistaxis regressed. Prednisolone was stopped on the fifth day and ampicillin-sulbactam course was completed after 14 days. At his outpatients' control after 15 days, total biliruin level regressed to $6.0 \mathrm{mg} / \mathrm{dL}$ and all other laboratory results normalized (Table 1). Microagglutination test (MAT) for serodiagnosis was later determined to be positive (L. icterohaemorrhagiae, titer: 1:200; serum was taken on the first day).

Our patient had a history of highly probable contact with mouse urine. He was initially diagnosed with Weil disease and antibiotic treatment was initiated immediately. His renal functions partially improved following intensive hydration and antibiotic treatment; however, thrombocytopenia worsened and total bilirubin level increased further. It has been reported that $50-80 \%$ of leptospirosis patients had thrombocytopenia, frequently accompanying renal failure $(1,2)$. Although its pathophysiology is not exactly clear, the following explanations were asserted: 1- direct toxicity of leptospira on the bone marrow, 2- thrombocyte consumption caused

TABLE 1. Laboratory results before and after prednisolone therapy (The prednisolone was started on Day 3)

\begin{tabular}{|c|c|c|c|c|c|c|c|c|}
\hline & Day 1 & Day 2 & Day 3 & Day 5 & Day 7 & Day 10 & Day 15 & Normal ranges \\
\hline Urea (mg/dL) & 67 & 52 & 40 & 27 & 15 & 12 & 14 & $0-26$ \\
\hline Creatinine (mg/dL) & 1.8 & 1.4 & 1.1 & 0.8 & 0.6 & 0.6 & 0.6 & $0.4-1.2$ \\
\hline $\begin{array}{l}\text { Thrombocyte count } \\
\left(\mathrm{x} 10^{3} / \mathrm{mm}^{3}\right)\end{array}$ & 32,000 & 26,000 & 19,000 & 42,000 & 75,000 & 186,000 & 271,000 & $150,000-450,000$ \\
\hline AST (U/L) & 87 & 72 & 70 & 86 & 82 & 70 & 41 & $0-45$ \\
\hline $\operatorname{ALT}(\mathrm{U} / \mathrm{L})$ & 49 & 45 & 41 & 62 & 79 & 56 & 42 & $0-40$ \\
\hline Total Bilirubin (mg/dL) & 13.1 & 11.9 & 14.7 & 11.4 & 9.7 & 8.2 & 6.0 & $0-1.0$ \\
\hline $\mathrm{CRP}(\mathrm{mg} / \mathrm{dL})$ & 25.4 & & 21.6 & & 16.5 & & 11.8 & $0-5$ \\
\hline
\end{tabular}

AST: aspartate aminotransferase; ALT: alanine aminotransferase; CRP: C-reactive protein 
by DIC, 3- immune-mediated thrombocyte destruction due to capillary vasculitis and inflammation (most favored mechanism), and 4-increased thrombocyte consumption secondary to vascular endothelial activation $(3,4)$. The presence of thrombocytopenia indicates severe disease; therefore, it should be closely monitored with regard to bleeding. After the addition of prednisolone, the platelet count rise and epistaxis regressed, supporting the idea that thrombocytopenia in leptospirosis appears secondary to vasculitis and inflammation.

There are limited data evaluating the use of prednisolone in Weil disease $(2,5,6)$. These reports showed that anti-inflammatory drugs like corticosteroids can reverse vasculitis by suppressing inflammation triggered by the disease and, as a result, reduce mortality. Similarly, we also found an effective response to corticosteroid therapy in a short period of time in our case. Based on this, we would like to emphasize that considering Weil disease in differential diagnosis of patients with fever, icterus, azotemia or hematological abnormalities is of significance. Antibiotic treatment should be initiated immediately upon suspicion of Weil disease in order to prevent mortality. Early administration of steroids helps to improve renal functions and prevents mortality in cases with thrombocytopenia. This approach could be important for centers where resources and patient transfer chances are limited.

\section{Ethics Committee Approval: N/A.}

Informed Consent: Written informed consent was obtained from patient who participated in this case.

Peer-review: Externally peer-reviewed.

Author contributions: Concept - B.E., Z.T., Y.K.; Design - B.E., Z.T., Y.K., Ş.Ö.; Supervision - Z.T., Y.K.; Resource - B.E., Z.T., Ş.Ö., Y.K.; Materials - Ş.Ö., Y.K.; Data Collection \&/or Processing - B.E.,
Z.T., Ş.Ö., Y.K.; Analysis \&/or Interpretation - B.E., Ş.Ö.; Literature Search - B.E., Z.T., Ş.Ö., Y.K.; Writing - B.E., Z.T., Ş.Ö., Y.K.; Critical Reviews - Ş.Ö., Y.K.

Conflict of Interest: No conflict of interest was declared by the authors.

Financial Disclosure: The authors declared that this study has received no financial support.

\section{REFERENCES}

1. Maroun E, Kushawaha A, El-Charabaty E, Mobarakai N, ElSayegh S. Fulminant Leptospirosis (Weil's disease) in an urban setting as an overlooked cause of multiorgan failure: a case report. J Med Case Rep 2011;5-7.

2. Gancheva G, Karcheva M. Severe leptospirosis observed in a man who had just returned from abroad. Balkan Med $J$ 2013;30:116-9. [CrossRef]

3. Sükran K, Tatar B, Ersan G, Topaloğlu S. A leptospirosis case presenting with thrombotic thrombocytopenic purpura. Balkan Med J 2013;30:436-8. [CrossRef]

4. Chierakul W, Tientadakul P, Suputtamongkol Y, Wuthiekanun V, Phimda K, Limpaiboon R, et al. Activation of the coagulation cascade in patients with leptospirosis. Clin Infect Dis 2008;46:254-60. [CrossRef]

5. Thunga G, John J, Sam KG, Khera K, Khan S, Pandey S, et al. Role of high-dose corticosteroid for the treatment of leptospirosis-induced pulmonary hemorrhage. J Clin Pharmacol 2012;52:114-6. [CrossRef]

6. Minor K, Mohan A. Severe leptospirosis: treatment with intravenous corticosteroids and supportive care. Am J Emerg Med 2013;31:449.e1-2. [CrossRef] 